УДК 533.15:546.291

\title{
Effect of Acid Leaching on Helium \\ and Neon Permeability \\ of Microspherical Membranes Based \\ on Cenospheres
}

\author{
Elena S. Rogovenko, \\ Vladimir V. Yumashev and Elena V. Fomenko* \\ Institute of Chemistry and Chemical Technology SB RAS \\ 50/24 Akademgorodok, Krasnoyarsk, 660036, Russia
}

Received 11.05.2015, received in revised form 16.06.2015, accepted 24.08.2015

\begin{abstract}
The microspherical membranes based on narrow fraction of cenospheres with high permeability to helium and high selectivity for He/Ne were recovered from cenosphere concentrate from Ekibastuz coal combustion. Acid leaching of the obtained microspherical membranes by $8.6 \mathrm{M} \mathrm{HNO}_{3}$ contribute to microporosity development in their shell (volume percentage of the micropore with predominant sizes of 5, 6.4 and 13 A was increased from 6.7 to $34.0 \mathrm{vol}$. \%). This led to increase in helium permeation at $T=298 \mathrm{~K}$ about to 2 times, i.e. up to a value of $2.27 \cdot 10^{-18}(\mathrm{~mol} \cdot \mathrm{m}) /\left(\mathrm{m}^{2} \cdot \mathrm{sec} \cdot \mathrm{Pa}\right)$. The obtained microspherical membranes are characterized by high selectivity $\alpha(\mathrm{He} / \mathrm{Ne})=170$ at $553 \mathrm{~K}$, and exceed the synthetic glass hollow microspheres $3 M$ K37 Glass Bubbles ( $3 M^{T M}$, USA) in helium permeation to 37-57 times, and the polymeric membrane material-(poly)sulphone in selectivity for $\mathrm{He} / \mathrm{Ne}$ to 34-52 times.
\end{abstract}

Keywords: cenospheres, inorganic membranes, helium, neon, permeability, selectivity.

DOI: $10.17516 / 1998-2836-2015-8-3-359-369$.

(C) Siberian Federal University. All rights reserved

* Corresponding author E-mail address: fom@icct.ru 


\title{
Влияние кислотного травления
}

\section{на проницаемость микросферических мембран на основе ценосфер в отношении гелия и неона}

\author{
Е.С. Роговенко, В.В. Юмашев, Е.В. Фоменко \\ Институт химии и химической технологии СО РАН \\ Россия, 660036, Красноярск, Академгородок, 50/24
}

\begin{abstract}
На основе узкой фракции ценосфер, выделенной из концентрата ценосфер от сжигания экибастузского угля, получены микросферические мембраны, характеризующиеся высоким уровнем гелиевой проницаемости в сочетании с высокой селективностью Не/Ne. Кислотное травление полученных микросферических мембран в 8,6 $\mathrm{M} \mathrm{HNO}_{3}$ способствовало развитию микропористости их оболочки (объемная доля микропор с преобладающими размерами 5, 6.4 и 13 А увеличилась с 6.7 до $34.0 \%$ ). Это привело к увеличению коэффициента гелиевой проницаемости при $T=298$ Кпримерно в 2 разадозначения $2.27 \cdot 10^{-18}\left(\right.$ моль:м)/( м $^{2} \cdot c \cdot$ Па).Полученные микросферические мембраны характеризуются высокой селективностью $\alpha(\mathrm{He} / \mathrm{Ne})=170$ при 553 К и превосходят синтетические стеклянные микросферы 3 M 637 Glass Bubbles (3M ${ }^{T M}$, США) по уровню гелиевой проницаемости в 34-57 раз, а полимерный мембранный материал (полисульфон) - по селективности в отношении Не/Ne в 34-52 раза.
\end{abstract}

Ключевые слова: иеносферы, неорганические мембраны, гелий, неон, проницаемость, селективность

\section{Введение}

Гелий является ключевым компонентом современных высокотехнологичных и наукоемких производств. Современная промышленная технология получения гелия основана на его выделении из природного и нефтяного газов энергоемким криогенным способом, который включает стадию низкотемпературной конденсации углеводородных фракций с получением гелиевого концентрата с содержанием основного компонента около 80 об. \% и несколько стадий очистки полученного концентрата от примесей метана, водорода, кислорода, азота, аргона и неона [1].

Альтернативным направлением извлечения гелия из газовых смесей служит энергоэффективная мембранная технология [1], для успешной реализации которой и получения гелия высокой чистоты (не более 0.005 об. \% примесей [2]) необходимы высокоселективные мембранные материалы, сочетающие в себе высокую проницаемость и селективность в отношении гелия.

Существующие мембранные материалы, такие как полимеры [3], цеолиты [4], металлорганические каркасные структуры [5, 6], характеризуются высокой гелиевой проницаемостью в диапазоне значений $10^{-11}-10^{-14}$ (моль'м)/(м²·c·Па), однако селективность разделения $\mathrm{He} / \mathrm{CH}_{4}$ для них составляет 2-92, в редких случаях достигая значений на уровне $10^{3}$. 
Наиболее подходящи для селективного извлечения гелия силикатные стекла, в том числе кварцевое стекло, которые характеризуются высоким уровнем селективности при разделении

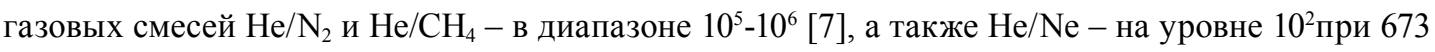
К [8]. Однако гелиевая проницаемость для таких материалов оказывается на 2-3 порядка ниже по сравнению с полимерными мембранами [3].

Из литературы $[9,10]$ известно, что одним из способов увеличения проницаемости стеклянных силикатных мембран является их травление минеральными кислотами $\left(\mathrm{HCl}, \mathrm{HNO}_{3}\right)$, приводящее к переходу отдельных компонентов стекла в раствор и формированию развитой пористой структуры. Так, автором [10] показано, что при травлении силикатного мембранного материала $\mathrm{HCl}$ гелиевая проницаемость при температуре 373 К достигает уровня $10^{-14}$ (моль·м)/ $\left(\mathrm{M}^{2} \cdot \mathrm{c} \cdot\right.$ Па), соответствующего проницаемости полимерных материалов, с сохранением высокой селективности $\alpha\left(\mathrm{He} / \mathrm{CH}_{4}\right)=10^{4}$. Следует отметить, что текстурные характеристики получаемых кислотным выщелачиванием пористых стекол связаны со структурой исходного стекла и зависят от его состава, температурного режима получения стекла, а также от условий кислотной обработки [11].

Основными текстурными характеристиками пористых неорганических мембран, определяющими эффективность разделения газов, выступают пористость и распределение пор по размеру [12]. В первую очередь для эффективного выделения гелия с высокой степенью чистоты представляют интерес микропористые мембраны со средним размером микропор менее 20 $\AA$ [13].

В частности, в работе [14] показано, что травление боросиликатного стекла с общим содержанием стеклообразующих оксидов $\Sigma\left(\mathrm{SiO}_{2}+\mathrm{B}_{2} \mathrm{O}_{3}\right)=90.6$ мас. \% в азотной кислоте (кипячение в $3 \mathrm{M} \mathrm{HNO}_{3}$ ) позволяет развить структуру ультрамикропор со средним диаметром $<10 \AA$. При обработке стекла другого состава с содержанием $\Sigma\left(\mathrm{SiO}_{2}+\mathrm{B}_{2} \mathrm{O}_{3}\right)=86.6$ мас. \% в соляной кислоте (3М HCl, 328 К) формируются поры со средним диаметром около $20 \AA$.

Наряду с известными силикатными стеклянными мембранами в процессе мембранного выделения высокочистого гелия могут быть использованы стеклокристаллические ценосферы. Ценоферы, или полые алюмосиликатные микросферы, являются одним из микросферических компонентов летучих зол, которые образуются в результате термохимических и фазовых превращений минеральных компонентов угля в процессе его пылевидного сжигания на ТЭС [15].

Авторами [16] показано, что раскристаллизация узких фракций ценосфер в окислительной атмосфере при температуре 1273-1373 К приводит к росту содержания кристаллической фазы муллита в оболочке ценосфер в интервале 4-48 мас. \% и увеличению коэффициента гелиевой проницаемости при температуре 298 К на два порядка. При этом селективность разделения Не/ $\mathrm{H}_{2}$ и $\mathrm{He} / \mathrm{Ne}$ при температуре 553 К составила 32 и 221 соответственно.

В работе [17] отмечена принципиальная возможность создания пористых материалов на основе узких фракций ценосфер. Показано, что при травлении соляной кислотой ценосфер с низким содержанием железа $\left(\mathrm{Fe}_{2} \mathrm{O}_{3}=1.7-2.6\right.$ мас. \%) формируется пористая структура с мономодальным распределением пор по размерам с максимумом $35 \AA$, а при травлении ценосфер с высоким содержанием $\mathrm{Fe}_{2} \mathrm{O}_{3}=3.0-14.7$ мас. \% наблюдается полимодальное распределение пор по размерам, наряду с главным максимумом $35 \AA$ присутствуют локальные максимумы 45, 70 
и $500 \AA$ А. Следовательно, для получения высокоселективных мембранных материалов на основе ценосфер представляют интерес образцы с низким содержанием железа в стеклофазе.

Целью работы являлось получение микросферических мембран на основе узкой фракции ценосфер и изучение влияния кислотного травления $\left(\right.$ в $\left.\mathrm{HNO}_{3}\right)$ на их диффузионные характеристики в отношении гелия и неона.

\section{Экспериментальная часть}

В качестве сырья для получения узкой фракции ценосфер гранулометрического класса $-0.063+0.05$ мм использовали концентрат ценосфер летучей золы от пылевидного сжигания каменного экибастузского угля на Рефтинской ГРЭС. Стабилизация химико-фазового состава и размера фракции ценосфер осуществлялась с применением многостадийной технологической схемы, подробно описанной в работах $[18,19]$.

Выделенная фракция ценосфер была охарактеризована набором физико-химических параметров, включающим химический и фазовый составы, насыпную плотность $\left(\rho_{\text {нас }}\right)$, среднюю толщину оболочки $(\delta)$, распределение глобул по размерам, средний диаметр глобул $\left(D_{c p}\right)$. Методики определения данных параметров приведены в работах $[18,19]$.

Обзорные снимки узкой фракции и индивидуальных глобул ценосфер получены с помощью электронного сканирующего микроскопа TM-1000 (Hitachi, Япония) при ускоряющем напряжении 15 кВ.

Концентрация азотной кислоты и длительность процесса травления подбирали опытным путем. Было установлено, что при кипячении ценосфер в $\mathrm{HNO}_{3}$ с концентрацией 8.6 моль/л в течение 1 ч достигается высокая степень извлечения ионов-модификаторов (97-98 \%). Дальнейшее увеличение концентрации кислоты и длительности травления практически не влияло на удаление ионов-модификаторов из оболочки ценосфер. Объемное соотношение твердой и жидкой фаз составляло 1:5. По завершении кислотной обработки образец ценосфер разделялся на три продукта: нижний, в котором содержатся осколки и разрушенные после травления глобулы, промежуточный, в котором содержится перфорированный продукт, и верхний целевой продукт, представляющий интерес для получения микросферических мембран. Верхний продукт был отделен от двух других и отмыт дистиллированной водой до $\mathrm{pH}=7.0$. Для эффективного отделения от перфорированных глобул полученный образец ценосфер последовательно подвергали процедурам вакуумирования при остаточном давлении 8 кПа в течение 30 мин и гидростатического разделения [20].

Исследование проницаемости полученных образцов ценосфер проводили в сравнении с синтетическими стеклянными микросферами 3М К37 Glass Bubbles фракции

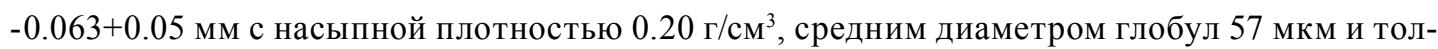
щиной оболочки 1.4 мкм, в которой содержание основных компонентов составило (мас. \%): $\mathrm{SiO}_{2}-70.62, \mathrm{CaO}-13.67, \mathrm{~B}_{2} \mathrm{O}_{3}-8.90, \mathrm{Na}_{2} \mathrm{O}-5.40, \mathrm{MgO}-0.63, \mathrm{SO}_{3}-0.29$ и $\mathrm{Fe}_{2} \mathrm{O}_{3}-0.12$. Оболочка полых микросфер содержит 99 мас. \% стеклофазы и 1 мас. \% кристобалита. Указанный синтетический микросферический материал производится фирмой $3 \mathrm{M}^{\mathrm{Tм}}$ (США) в промышленных масштабах и по содержанию $\mathrm{SiO}_{2}$ и физическим характеристикам (средний диаметр и толщина оболочки) максимально близок узкой фракции ценосфер, изучаемой в данной работе. 
Проницаемость микросферических мембран изучали в отношении гелия и неона на вакуумной статической установке, представленной на рис. 1, в режиме диффузии газа из объема реактора внутрь глобул при давлении 30 кПа в интервале температур 298-673 К в случае гелия и 553-773 K для неона, с шагом в $100 \mathrm{~K}$. Диффузия газов через оболочку осуществлялась за счет разности парциальных давлений снаружи и внутри глобул. Определение проницаемости $Q$, моль/(Па·с·г) микросферических мембран основывалось на измерении падения давления газа во времени после перепуска в реактор, заполненный образцом [21]:

$$
Q=d P / d t \cdot\left(V_{0} / T_{0}+V_{p} / T_{1}\right) / P_{\text {out }} \cdot R,
$$

где $V_{0}$ - объем гребенки, л; $T_{0}$ - комнатная температура, К; $V_{p}$ - объем реактора, л; $T_{1}$ - температура в реакторе, К; $P_{\text {out }}$ - давление гелия снаружи частиц в момент времени $t$, Па; $R$-универсальная газовая постоянная, 8.314 (л:Па)/(мольК).

Относительная стандартная ошибка определения проницаемости не превышала $10 \%$.

Значения коэффициентов проницаемости микросферических мембран $K_{H e}$ и $K_{N e}$ (моль'м)/ $\left(\mathrm{M}^{2} \cdot \mathrm{c} \cdot\right.$ Па) были рассчитаны по уравнению (2) с учетом содержания стеклофазы при условии, что проницаемость кристаллических фаз на несколько порядков ниже, чем у стеклофазы [22]:

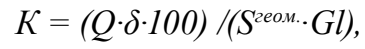

где $Q$ - проницаемость газа через оболочку микросферических мембран, моль/(Па·с·г); $\delta$ - тол-

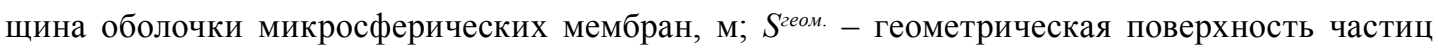
образца, рассчитанная как сумма поверхностей идентичных сфер со средним диаметром $\mathrm{D}_{\mathrm{cp}}$ (мкм), м²/г; $G l$ - доля стеклофазы в образце ценосфер, мас. \%.

Значения селективности были рассчитаны как отношение коэффициентов проницаемости индивидуальных газов, т.е. $\alpha(\mathrm{He} / \mathrm{Ne})=K_{\mathrm{He}} / K_{\mathrm{Ne}}$.

Также для полученных узких фракций ценосфер были определены текстурные характеристики: удельная поверхность $\left(S_{5 E T}\right)$, объем пор ( $V^{\text {total }}$ - общий объем и $V^{\text {mic }}$ - объем микропор) и распределение пор по размерам.


Рис. 1. Схема диффузионной установки для определения газовой проницаемости микросферических мембран 
Изучение текстурных характеристик проводили на сорбционном анализаторе ASAP 2020MP-C («Micromeritics», США) посредством определения изотерм низкотемпературной адсорбции азота (чистотой $99.999 \%$ ) при температуре 77 К в интервале $\mathrm{P} / \mathrm{P}_{0}=10^{-7} \div 0.998$ с высокой степенью разрешения в области объемного заполнения микропор $\mathrm{P} / \mathrm{P}_{0}<0.01$ (с инкрементным приростом количества адсорбированного азота $0.015 \mathrm{~cm}^{3} / \Gamma$ СТД). Расчет площади удельной поверхности осуществляли по методу БЭТ с корректировкой интервала $\mathrm{P} / \mathrm{P}_{0}$ в соответствии с методом, учитывающим наличие микропор, предложенным авторами $[23,24]$ и впоследствии стандартизованным для микро-мезопористых материалов [25]. Анализ микропористости, а именно определение объема, удельной поверхности микропор и внешней удельной поверхности, выполняли с помощью сравнительного $t$-метода с использованием уравнения Harkins-Jura $[26,27]$ для расчета толщины статистического слоя адсорбата. Дополнительно были рассчитаны распределения микро- и мезопор по размеру с помощью метода NLDFT (non-local density functional theory) $[28,29]$, базирующегося на теории функционала плотности. Относительная стандартная ошибка при описании экспериментальных данных с помощью указанной модели не превышала $5 \%$.

\section{Обсуждение результатов}

Из концентрата ценосфер летучей золы от пылевидного сжигания каменного экибастузского угля была выделена фракция немагнитных неперфорированных ценосфер $H M R 5 A$, соответствующая узкому гранулометрическому классу $-0.063+0.05$ мм низкой насыпной плотности 0.37 г $\mathrm{cm}^{3}$, со средним диаметром глобул 60 мкм, толщиной оболочки 2.8 мкм.

Согласно данным химического анализа, выделенная фракция ценосфер представляет собой многокомпонентную систему преимущественно алюмосиликатного состава с содержанием основных макрокомпонентов $\mathrm{SiO}_{2}$ и $\mathrm{Al}_{2} \mathrm{O}_{3} 61$ и 35 мас. \% соответственно. Оболочка ценосфер состоит из стеклофазы и кристаллических фаз кварца, муллита и кальцита (табл. 1). Стоит отметить, что большинство глобул во фракции ценосфер HMR $5 A$ имеют пористую оболочку (рис. 2a). При этом отличительной особенностью образца ценосфер HMR5A является наличие планарно-ориентированных кристаллитов муллита (рис. 26), которые придают дополнительные прочностные характеристики ценосферам, что позволяет использовать их в качестве мембран при высоких давлениях.

Травление фракции ценосфер HMR5A азотной кислотой привело к изменению фазового состава образца $H M R 5 A \mathrm{HNO}_{3}$, что выражается в исчезновении фазы кальцита и уменьшении содержания кварца до 0.9 мас. \%. При этом кислотная обработка приводит к значительному развитию пористой структуры оболочки образца $H M R 5 A H O_{3}$ за счет выщелачивания

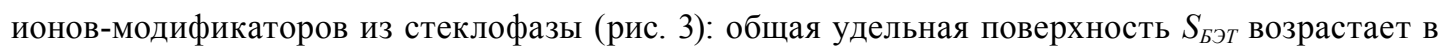
14 раз, в том числе удельная поверхность микропор $S^{\text {mic }}$ - в 25 раз, а общий объем пор $V^{\text {otal }}$ - в 5 раз, причем объемная доля микропор увеличивается с 6.7 до $34 \%$ по сравнению с исходным образцом HMR5A (табл. 2). Анализ функций NLDFT-распределения в области микропор (рис. 3) показал, что в оболочке образца $H M R 5 A H N O_{3}$ наблюдается развитие однородной микропористой структуры, сопровождающееся значительным увеличением вклада уже присутствующих в исходном образце пор с шириной $13 \AA$ и появлением новых микропор меньшего размера -5 и $6.4 \AA$. В области мезопор наблюдается развитие пор в интервале $20-100 \AA$ 
Таблица 1. Химический и фазовый состав исходной узкой фракции ценосфер

\begin{tabular}{|c|c|}
\hline & \multicolumn{1}{c|}{ Образец 5A } \\
\hline \multicolumn{2}{|c|}{ Химический состав, мас. \% } \\
\hline $\mathrm{SiO}_{2}$ & 60.80 \\
\hline $\mathrm{Al}_{2} \mathrm{O}_{3}$ & 34.65 \\
\hline $\mathrm{Fe}_{2} \mathrm{O}_{3}$ & 1.02 \\
\hline $\mathrm{CaO}$ & 1.03 \\
\hline $\mathrm{MgO}$ & 1.12 \\
\hline $\mathrm{Na}_{2} \mathrm{O}$ & 0.31 \\
\hline $\mathrm{K}_{2} \mathrm{O}$ & 0.51 \\
\hline $\mathrm{SO}_{3}$ & 0.10 \\
\hline $\mathrm{P}_{2} \mathrm{O}_{5}$ & 0.10 \\
\hline п.п.п. & 0.14 \\
\hline & \\
\hline Стеклофаза & 68.9 \\
\hline Муллит & 29.8 \\
\hline Кварц & 1.2 \\
\hline Кальцит & 0.1 \\
\hline & Фазовый состав, мас. \% \\
\hline & \\
\hline
\end{tabular}
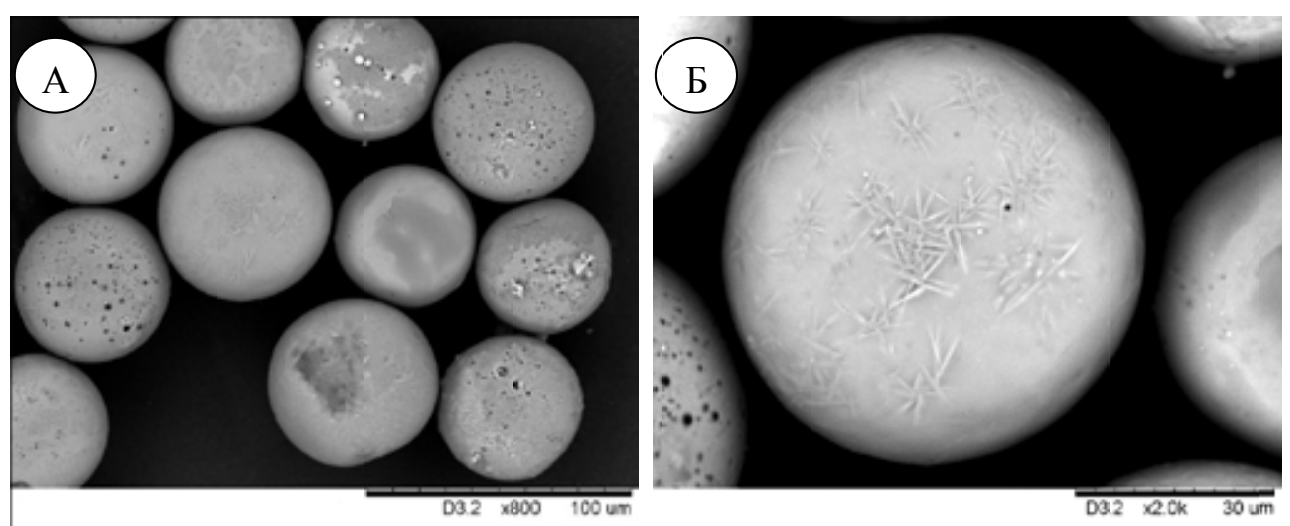

Рис. 2. SЕM-снимки образцов ценосфер: (A) HMR5A обзорный снимок узкой фракции, (Б) $H M R 5 A$ индивидуальная глобула

с преобладающими размерами 27, 34 и $47 \AA$ А. Следовательно, травление азотной кислотой ценосфер алюмосиликатного состава приводит в большей степени к формированию микропористой структуры образца $\mathrm{HMR}_{\mathrm{A}} \mathrm{HNO}_{3}$, т.е. к развитию пор с размерами менее $20 \AA$, что, в свою очередь, способствует увеличению коэффициента гелиевой проницаемости через стеклофазу относительно исходного образца $H M R 5 A$ примерно в 2 раза при температуре 298 К, достигая значения $2.27 \cdot 10^{-18}$ (моль $\cdot$ ) $/\left(\mathrm{M}^{2} \cdot \mathrm{c} \cdot\right.$ Па). При этом селективность в отношении Не/ $\mathrm{Ne}$ для травленого образца ценосфер $\mathrm{HMR}_{\mathrm{A}} \mathrm{HNO}_{3}$ по сравнению с исходным HMR5A при температуре 553 К снижается незначительно (т.е. остается в рамках одного порядка величины) и составляет 170

$$
-365-
$$




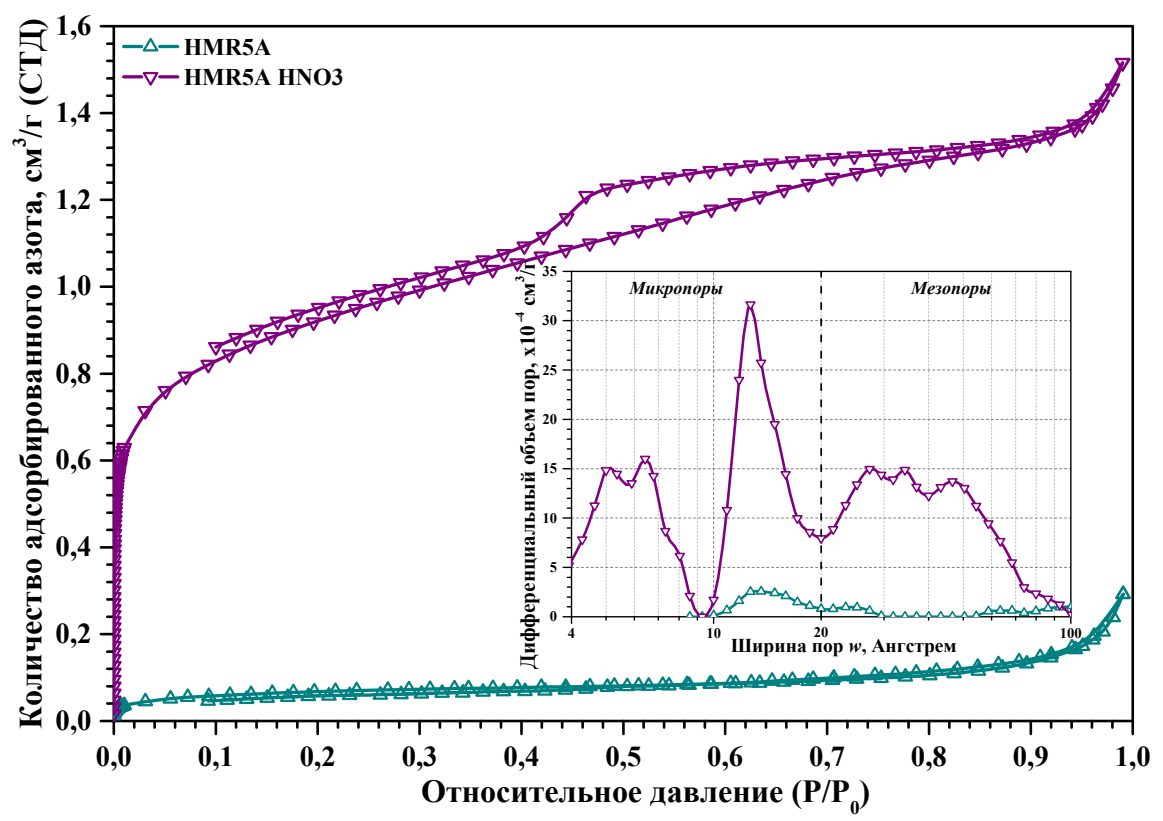

Рис. 3. Изотермы низкотемпературной адсорбции-десорбции азота для исходного и травленого образцов ценосфер и функции распределения микро- и мезопор по размерам для исходного и травленого образцов ценосфер, рассчитанных по методу NLDFT [28, 29]

Таблица 2. Текстурные характеристики исходной и травленой узкой фракции ценосфер

\begin{tabular}{|c|c|c|c|c|c|}
\hline \multirow{2}{*}{ Образец } & \multicolumn{3}{|c|}{ 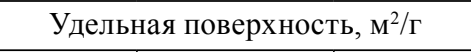 } & \multicolumn{2}{|c|}{ Объем пор, х10 $0^{-4} \mathrm{~cm}^{3} / \mathrm{I}$} \\
\hline & $\mathrm{S}_{\mathrm{EET}}$ & $\mathrm{S}^{\mathrm{mic}}$ & $\mathrm{S}^{\mathrm{ext}}$ & $\mathrm{V}^{\text {mic }}$ & $\mathrm{V}^{\text {total }}$ \\
\hline HMR5A & 0.24 & 0.07 & 0.17 & 0.3 & 4.5 \\
\hline $\mathrm{HMR} \mathrm{A} \mathrm{HNO}_{3}$ & 3.32 & 1.86 & 1.46 & 8.0 & 23.5 \\
\hline
\end{tabular}

$V^{\text {rotal }}$ - общий объем пор рассчитывался при значении $P / P_{0}=0.99$.

Таблица 3. Диффузионные характеристики исходных и травленых узких фракций ценосфер и микросфер при температурах 298 и 553 К в расчете на стеклофазу

\begin{tabular}{|c|c|c|c|c|c|c|}
\hline \multirow{3}{*}{ Образец } & \multicolumn{3}{|c|}{$\begin{array}{c}\text { Коэффициент проницаемости, } \\
\text { х10-18 (моль'м)/(м²·c·Па) }\end{array}$} & \multirow{3}{*}{$\frac{\alpha(\mathrm{He} / \mathrm{Ne})}{553 \mathrm{~K}}$} & \multirow{2}{*}{\multicolumn{2}{|c|}{$\mathrm{E}_{\mathrm{a}}$, кДж/моль }} \\
\hline & \multirow{2}{*}{$\begin{array}{c}298 \mathrm{~K} \\
\mathrm{~K}_{\mathrm{He}}\end{array}$} & \multicolumn{2}{|c|}{$553 \mathrm{~K}$} & & & \\
\hline & & $\mathrm{K}_{\mathrm{He}}$ & $\mathrm{K}_{\mathrm{Ne}}$ & & $\mathrm{He}$ & $\mathrm{Ne}$ \\
\hline HMR5A & 1.35 & 174 & 0.67 & 260 & 26 & 42 \\
\hline $\mathrm{HMR} \mathrm{A} \mathrm{HNO}_{3}$ & 2.27 & 156 & 0.92 & 170 & 23 & 37 \\
\hline 3M K37 & 0.04 & 21 & 0.05 & 420 & 33 & 51 \\
\hline $3 \mathrm{M} \mathrm{K} 37 \mathrm{HNO}_{3}$ & 0.25 & 56 & 0.24 & 233 & 29 & 42 \\
\hline
\end{tabular}


(табл. 3), что превышает известное значение селективности $\mathrm{He} / \mathrm{Ne}$ для полимерного материала полисульфона в 34-52 раз [30]. Энергии активации процессов диффузии гелия и неона через оболочку ценосфер HMR5A характеризуются значениями 26 и 42 кДж/моль соответственно, которые снижаются после травления образца в азотной кислоте до значений 23 и 37 кДж/моль соответственно за счет химических и структурных изменений в стеклофазе, вызванных удалением из нее ионов-модификаторов.

Сравнительное исследование диффузионных свойств синтетических стеклянных микросфер $3 M K 37$ показало, что при их травлении $8.6 \mathrm{M} \mathrm{HNO}_{3}$ наблюдается увеличение удельной по-

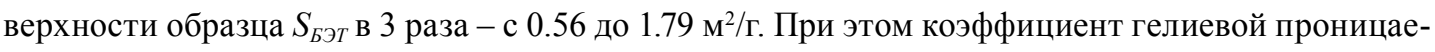
мости при температуре 298 К увеличился в 6 раз по сравнению с исходным образцом (табл. 3). Однако, несмотря на рост коэффициента гелиевой проницаемости, синтетические микросферы $3 M K 37$ более чем на порядок уступают ценосферам по уровню проницаемости (табл. 3). Селективность в отношении Не/Ne при температуре 553 К для травленого образца $3 \mathrm{M} \mathrm{K} 37 \mathrm{HNO}_{3}$ снижается примерно в 2 раза до значения 233 по сравнению с исходными микросферами $3 M K 37$. Энергии активации процессов диффузии гелия и неона через стеклянную оболочку микросфер характеризуются, по сравнению с образцом ценосфер $H M R 5 A$, более высокими значениями 33 и 51 кДж/моль для исходного и 29 и 42 кДж/моль - для травленого образца соответственно.

Наблюдается общая для всех изучаемых образцов ценосфер/микросфер (включая образцы после травления) закономерность: повышение температуры диффузионного процесса с 553 до 673 К вызывает рост коэффициентов проницаемости $K_{H e}$ и $K_{N e}$ в 2.0-2.5 и 3.0-3.5 раза соответственно и, как следствие, снижение селективности $\alpha(\mathrm{He} / \mathrm{Ne})$ в 1.5-2.0 раза.

\section{Выводы}

Из концентрата ценосфер летучей золы от сжигания экибастузского угля выделена узкая фракция немагнитных неперфорированных ценосфер $H M R 5 A$ размером $-0.063+0.05$ мм низкой насыпной плотности 0.37 г/см ${ }^{3}$, со средним диаметром глобул 60 мкм, с тонкой оболочкой 2.8 мкм.

Установлено, что в результате травления узкой фракции ценосфер $H M R 5 A$ в 8,6 $\mathrm{M} \mathrm{HNO}_{3}$ коэффициент гелиевой проницаемости стеклофазы при температуре 298 К увеличивается в

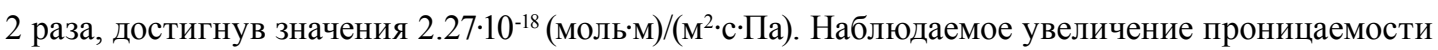
связано с развитием микропористой структуры (объем микропор увеличился с 6.7 до 34 \%) с преобладающими размерами микропор 5, 6.4 и $13 \AA$. Показано, что узкие фракции исходных и травленых в $8.6 \mathrm{M} \mathrm{HNO} 3$ ценосфер характеризуются высокими значениями селективности в отношении $\mathrm{He} / \mathrm{Ne}$, которые при температуре 553 К составляют 260 и 170 соответственно.

Полученные микросферические мембраны по уровню гелиевой проницаемости в 34-57

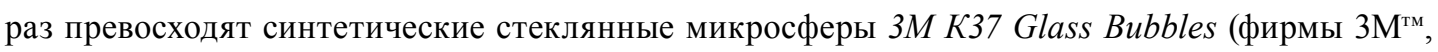
США), а по селективности в отношении $\mathrm{He} / \mathrm{Ne}$ в 34-52 раз - полимерный мембранный материал полисульфон.

Авторы выражают благодарность сотруднику ИХХТ СО РАН (2. Красноярск) Л.А. Соловьеву за помощь в проведении и интерпретации результатов количественного рентгенофазового анализа.

$$
-367-
$$




\section{Список литературы}

1. Молчанов С.А. Особенности выделения гелия из природного газа. М.: Недра, 2011. 285 c. [Molchanov S.A. Specialities of helium capture from natural gas. Moscow: Nedra, 2011. 285 p. (In Russ.)]

2. ТУ 0271-13531323949-2005. Гелий газообразный (сжатый). [Technical Specification 027113531323949-2005. Gaseous (compressed) helium. (In Russ.)]

3. Robeson L.M. The upper bound revisited. Membr. Sci. 2008. Vol. 320, P. 390-400.

4. Cui Y., Kita H., Okamoto K. Preparation and gas separation performance of zeolite T membrane. Mater. Chem. 2004. Vol. 14, P. 924-932.

5. Cao F., Zhang C., Xiao Y., Huang H., Zhang W., Liu D., Zhong C., Yang Q., Yang Z., Lu X. Helium recovery by a Cu-BTC metal-organic framework membrane. Ind. Eng. Chem. Res. 2012. Vol. 51, P. 11274-11278.

6. Takamizawa S., Takasaki Y., Miyake R. Single-crystal membrane for anisotropic and efficient gas permeation. Am. Chem. Soc. 2010. Vol. 132, P. 2862-2863.

7. Николаев Н.И. Диффузия в мембранах. М.: Химия, 1980. 232 с. [Nikolaev N.I. Diffusion in membranes. Moscow: Khimiya, 1980. 232 p. (In Russ.)]

8. Leiby C. C., Chen C. L. Diffusion coefficients, solubilities, and permeabilities for $\mathrm{He}, \mathrm{Ne}, \mathrm{H}_{2}$, and $\mathrm{N}_{2}$ in Vycor glass. Appl. Phys. 1960. Vol. 31, P. 268-274.

9. Enke D., Janowskia F., Schwiegerb W. Porous glasses in the 21st century - a short review. Microporous and Mesoporous Materials. 2003. Vol. 60, P. 19-30.

10. Kuraoka K., Hirano T., Yazawa T. High-selectivity, high-flexibility glass hollow-fiber membrane for gas separation. Chem. Commun. 2002. P. 664-665.

11. Пак В.Н., Гавронская Ю.Ю., Буркат Т.М. Пористые стекла и наноструктурированные материалы на их основе. СПб: РГПУ им. А.И. Герцена, 2013. 129 с. [Pak V.N., Gavronskaya Yu.Yu., Burkat T.M. Porous glasses and nanostructured materials based on them. St. Petersburg: Publishing of the Russian State Pedagogical University named after A.I. Herzen, 2013. 129 p. (In Russ.)]

12. Burggraaf A.J., Cot L., editors. Chapter 9. Transport and separation properties of membranes with gases // In: Fundamentals of Inorganic Membrane Science and Technology. Amsterdam, Lausanne, New York, Shannon, Tokyo: Elsevier Science B.V., 1996. P. 331-427.

13. Shelekin A.B., Dixon A.G., Ma Y.H. Theory of gas diffusion and permeation in inorganic molecular-sieve membranes. AlChe J. 1995. Vol. 41(1), P. 58-67.

14. Yazawa T., Kuraoka K., Du W.-F. Effect of cooling rate on pore distribution in quenched sodium borosilicate glasses. Phys. Chem. 1999. Vol. 103, P. 9841-9845.

15. Vassilev S. V., Vassileva C. G. A new approach for the classification of coal fly ashes based on their origin, composition, properties, and behavior. Fuel. 2007. Vol. 86, P. 1490-1512.

16. Fomenko E. V., Rogovenko E. S., Solovyov L. A., Anshits A. G. Gas permeation properties of holow glass-crystalline microspheres. RSC Advances. 2014. Vol. 4, P. 9997-10000.

17. Anshits N. N., Vereshchagina T. A., Bayukov O. A., Salanov A. N., Anshits A. G. The nature of nanoparticles of crystalline phases in cenospheres and morphology of their shells. Glass Physics and Chemistry. 2005. Vol. 31(3), P. 306-315. 
18. Anshits N. N., Mikhailova O. A., Salanov A. N., Anshits A. G. Chemical composition and structure of the shell of fly ash non-perforated cenospheres produced from the combustion of the Kuznetsk coal (Russia). Fuel. 2010. Vol. 89(8), P. 1849-1862.

19. Fomenko E. V., Anshits N. N., Solovyov L. A., Mikhaylova O. A., Anshits A. G Composition and morphology of fly ash cenospheres produced from the combustion of Kuznetsk Coal. Energy and Fuels. 2013. Vol. 27, P. 5440-5448.

20. Панкова М.В., Фоменко Е.В., Аншиц А.Г. Микросферические мембраны и композитные сорбенты на основе ценосфер. Состав, строение и физико-химические свойства. Saarbrücken, Germany: LAP LAMBERT Academic Publishing GmbH \& Co. KG, 2012. 126 c. [Pankova M.V., Fomenko E.V., Anshits A.G. Microspherical membranes and composite sorbents based on cenospheres. Composition, structure and physicochemical properties.Saarbrücken, Germany: LAP LAMBERT Academic Publishing GmbH \& Co. KG, 2012. 126 p. (In Russ)]

21. Chernyh Ya. Yu., Vereshchagin S. N. Helium Permeability Studies of Fly Ash Cenospheres. Journal of Siberian Federal University. Chemistry.2011. Vol. 4(2), P. 135-147.

22. Sheelby J. E. Introduction to glass science and technology. Cambridge: The Royal Society of Chemistry, 2005. 308 p.

23. Rouquerol J., Rouquerol F., Grillet Y., Triaca M. Quasi-equilibrium nitrogen adsorption gravimetry: comparison with volumetry for the determination of surface areas and pore size distributions. Thermochimica Acta. 1986. Vol. 10, P. 89-96.

24. Lowell S., Shields J. E., Thomas M. A., Thommes M. Characterization of porous solids and powders: surface area, pore size, and density. New York: Springer Science+Business Media, 2004. $363 \mathrm{p}$.

25. ISO 9277:2010-09 (E). Determination of the specific surface area of solids by gas adsorption BET method.

26. Harkins W. D., Jura G. A vapor adsorption method for the determination of the area of a solid without the assumption of a molecular area, and the areas occupied by nitrogen and other molecules on the surface of a solid. Journal of the American Chemical Society. 1944. Vol. 66, P. 1366-1373.

27. Webb P., Orr C. Analytical methods in fine particle technology. Norcross GA.: Micromeritics Instrument Corporation, 1997. $301 \mathrm{p}$.

28. Lastoskie C., Gubbins K. E., Quirke N. Pore size distribution analysis of microporous carbons: a density functional theory approach. Journal of Physical Chemistry. 1993. Vol. 97, P. 4786-4796.

29. Landers J., Gor G. Yu., Neimark A. V. Density functional theory methods for characterization of porous materials. Colloids and Surfaces A: Physicochemical and Engineering Aspects. 2013. Vol. 437, P. 3-32.

30. Патент 2441693 РФ. Кузьменко И.Ф., Горохов В. А., Талакин О. Г. Устройство для концентрирования неона в газовых смесях, содержащих неон. Опубл. 27.12.2010. [Patent 2441693 RU. Kuz'menko I.F., Gorokhov V.A., Talakin O.G. Device for neon concentration in air mixtures containing neon. Publ. Date 27.12.2010 (InRuss.)] 